\title{
Aproximación al estudio de las antigüedades en la América española en el siglo XVIII a través de tres instrucciones
}

\author{
Alicia León Gómez y Raquel Gil Fernández \\ Universidad Internacional de La Rioja \\ alicia.leon@unir.net / raquel.gilfernandez@unir.net
}

Fecha recepción 09.11.2016 / Fecha aceptación 10.01.2017

\section{Resumen}

En este artículo analizamos tres instrucciones emitidas en el siglo XVIII en las que se alude al tratamiento de vestigios arqueológicos de la América española. A través de ellas podemos observar la evolución en la concepción imperante en cada momento sobre los restos arqueológicos, y cómo se va trascendiendo desde la perspectiva anticuarista hasta una nueva corriente en la que se empiezan a tratar como fuente de información. Centrándonos en los capítulos dedicados a antigüedades, analizaremos el cuerpo de las instrucciones redactadas por Franco Dávila, Antonio de Ulloa y José de Estacharía y el tratamiento que se recomienda en las mismas para los restos muebles e inmuebles hallados en la América Colonial.

\section{Palabras clave}

Instrucciones, Historia de la arqueología de la América Colonial, anticuarismo, novatores, antigüedades americanas.

\section{Abstract}

In this article, we analyse three sets of instructions, issued in the $18^{\text {th }}$ century, referring to the treatment of the archaeological vestiges of Spanish America. Through them we can trace the evolution of the prevailing idea concerning archaeological remains at every moment, and how a shift from the antiquarian perspective to a new trend will allow them to be treated as a source of information. We analyse the body of instructions written by Franco Davila, Antonio de Ulloa and José de Estacharía, focusing on the chapters dedicated to antiques, which recommended treatment for the remains and personal property found in Colonial America.

\section{Key words}

Instructions, History of the American Colonial archaeology, antiquarianism, novatores, American antiques 


\section{Introducción}

El siglo XVIII, en el ámbito cultural, se caracterizó por la convivencia de dos concepciones ideológicas contrapuestas, representadas de un lado por el sector más tradicional y de otro por las nuevas tendencias surgidas en el seno de la denominada Ilustración, que tiene sus orígenes en la Inglaterra de finales del siglo XVII, donde se empiezan a cuestionar la sociedad, cultura y religión bajo el prisma de la razón ${ }^{1}$. Partiendo de esta premisa, la Ilustración se caracteriza por la defensa del libre pensamiento de los científicos frente a los límites impuestos por la Teología, siendo la razón el arma más poderosa para el conocimiento².

Esta nueva reivindicación de la razón, como característica imprescindible y primordial para el conocimiento, se extendió a todos los ámbitos del saber y, por supuesto, al estudio de las antigüedades, que no permaneció al margen, aunque hasta ese momento se había caracterizado por un anticuarismo representado por eruditos dedicados al coleccionismo y catalogación, con poca atención a la investigación científica propugnada por los ilustrados. En esta nueva corriente de pensamiento histórico los restos arqueológicos se empezaron a considerar como fuente de información no contaminada para la Historia ${ }^{3}$. Este nuevo planteamiento de estudio es conocido como Crítica Histórica y está representado, entre

1. Ver AAVV, La España moderna. Madrid, 1992. A. León Gómez, El estudio de los Edificios de espectáculos romanos en la España del siglo XVIII. Análisis del uso de la imagen en los inicios de la arqueología española, Saarbrücken (Alemania), 2012.

2. AAVV, La España...op.cit. 1992. Sobre el movimiento ilustrado ver -entre la ingente bibliografíaA. Mestre Sanchís, "Conciencia Histórica e Historiográfica. La época de la ilustración. El estado y la cultura (1759-1808)”, en Historia de España, Tomo XXXI (1), Madrid, 1996; A. Mestre Sanchís, "Historiografía”, en Historia literaria de España en el siglo XVIII, Madrid, 1996.

3. En la España de finales del siglo XVI, tenemos un claro ejemplo de un pionero de esta nueva corriente histórica, Antonio Agustín escribió «yo mas fe doi a las medallas y tablas piedras que a todo lo que escriben 
otros, por el P. Jean Mabillon ${ }^{4}$ con su obra De Re Diplomatica (1681) y Bernard Montfaucon con su L'Antiquité expliquée et representée en figures (1719-1724) ${ }^{5}$. En España este nuevo movimiento, estuvo representado por los llamados novatores, que entraron en conflicto con la corriente más tradicionalista defendida por eruditos que utilizaban como base de sus estudios los «falsos cronicones». Éstos recibieron el apoyo del poder eclesiástico y civil, en pro del enaltecimiento del orgullo nacional a lo largo del siglo XVII y principios del XVIII. En España, dentro del movimiento novator podemos destacar a intelectuales de la talla del marqués de Mondéjar, el cardenal benedictino Sáenz de Aguirre o el sevillano Nicolás Antonio que escribió Censura de Historias fabulosas, obra póstuma publicada por Gregorio Mayans ${ }^{6}$ en 1742 que, junto con su maestro el pre-ilustrado Manuel Martí, intentó promover la Crítica Histórica entre los estudiosos de la época ${ }^{7}$.

los escritore» en su obra Diálogos de Medallas (1587, 377). ["Yo doy mas fe a las medallas, a las lápidas y las piedras, que a todo aquello que dicen los escritores"]

4. Jean Mabillon fue uno de máximos responsables de la escuela de los benedictinos de Saint Maur (París), conocidos como los maurinos, entre los que surgió la nueva corriente de estudio conocida como la Crítica Histórica. E. Gran-Aymerich, El nacimiento de la arqueología moderna, 1798-1945, Zaragoza, 2001.

5. Sobre Bernard de Montfaucon ver E. Gran-Aymerich, El nacimiento...op. cit.; G. Mora, Historia de mármol, Madrid, 1998; J. Beltrán y M. Belén (eds.), El clero y la arqueología española, Sevilla, 2003.

6. Nació en Oliva (Valencia) el 9 de mayo de 1699. En 1714 inicia sus estudios de Derecho en la Universidad de Valencia entrando en contacto con novatores como Tosco, Corachán, etc. En 1719 conoció a su gran maestro y amigo el deán Martí quien lo inició en los estudios de las lenguas clásicas y las antigüedades. En 1723 consiguió una cátedra en la Universidad de Valencia y en 1742 funda la Academia Valenciana. Sus publicaciones fueron muy prolíferas iniciándolas en 1723 con Ad quinque iurisconsultum fragmenta comentarii y finalizando un año antes de su muerte con su Idea editonis de l'Opera Omnia de Vives. En 1781 falleció a la edad de 82 años. Sobre G. Mayans ver A. Mestre Sanchís, Mayans y Siscar, G. Epistolario II. Mayans y Burriel. Transcripción, notas y estudio preliminar de A. Mestre, Valencia, 1972; A. Mestre Sanchís, Mayans y Siscar, G. Epistolario III. Mayans y Martí. Transcripción, notas y estudio preliminar de A. Mestre, Valencia, 1973; A. Mestre Sanchís, Don Gregorio Mayans y Siscar. Entre la erudición y la política, Valencia, 1999.

7. Manuel Martí nació en Oropesa (Castellón) en 1663. A los diez años se instala en Castellón para estudiar latín y en 1676, se dirigió a Valencia para estudiar Teología. Se caracterizaba por una fuerte inquietud intelectual que le hizo entrar en contacto con las Academias del Alcázar y del Parnaso, representantes de estas nuevas corrientes. Viajó a Italia en dos ocasiones, donde residió varios años, adquiriendo unos conocimientos imprescindibles para su formación histórica y anticuaria. Entró en contacto con la arqueología en Italia, materializando sus conocimientos luego en España en las intervenciones arqueológicas realizadas en el teatro de Sagunto y el anfiteatro de Itálica, según cita su biógrafo y discípulo Mayans. En este fructífero período profesional en Italia escribió varias obras, como Amorum. Sobre el Deán Martí ver L. Gil, Tres humanistas españoles, Madrid, 1975; L. Gil, Emmanuelis Martini, Ecclesiae Alonensis Decari. Vita, scriptore Gregorio Mainasiano, generoso Valentino. Estudio premilimar, Valencia, 1977; L. Gil, "Los apuntes autobiográficos del Deán Martí”. BRAE LVIII, p. 47-101; J. Beltrán, "El estamento eclesiástico en la historia de la arqueología española del Antiguo Régimen (siglos XVI-XVIII)” en J. Beltrán y Ma Belén (eds) El clero y la arqueología española (II Reunión andaluza de historiografía arqueológica, Sevilla, 2003; A. Mestre Sanchís, Manuel Martí, el deán de Alicante, Alicante, 2003; A. León Gómez, Imágenes arqueológicas de la 
A pesar de los esfuerzos de los novatores, la Ilustración no comenzó a consolidarse en España hasta mediados del XVIII debido, en parte, a todos los avatares políticos de la primera mitad de la centuria. La entrada de la Ilustración viene de la mano de la nueva dinastía, los Borbones, que se identifican claramente con la cultura clásica ${ }^{8}$ y por ende, con el rechazo por el Barroco. Esto provocó una tendencia en los estudios históricos hacia el mundo clásico, sin olvidar la existencia de los dedicados a las épocas prerromana y medieval (por ejemplo, el trabajo de las Antigüedades Árabes de España de José de Hermosilla) ${ }^{9}$, aunque éstos últimos no se consolidarán hasta el siglo XIX, cuando caiga en desgracia el clasicismo al identificarse políticamente con el Absolutismo del XVIII. Del mismo modo las antigüedades americanas empezaron a ocupar un lugar entre los eruditos de la época que se sintieron atraídos por las mismas.

A finales del siglo XVIII y principios de la centuria siguiente, especialmente tras la Revolución francesa, los restos arqueológicos se empezaron a considerar no sólo como fuentes de información sino como parte de un patrimonio nacional vinculado, cada vez más, a un sentimiento «patriótico y nacional». Según Gran-Aymerich «a finales del siglo XVIII y principios del XIX asistimos a las primeras tentativas de organizar y centralizar la arqueología nacional, pero no puede olvidarse el papel de las sociedades eruditas, numerosas ya en esta época, que celosas de su independencia del estado y del mundo erudito oficial, multiplicarán sus esfuerzos por coordinar sus acciones» ${ }^{10}$. En efecto, ese nuevo concepto de patrimonio nacional relacionado con los restos arqueológicos, donde las instituciones desempeñaron un papel muy importante en su salvaguarda, se opone a la utilización política a la que fueron sometidos en el siglo XVIII, generalmente en el marco del Despotismo Ilustrado ${ }^{11}$.

España ilustrada. El teatro romano de Sagunto en el siglo XVIII, Sevilla, 2006; A. León Gómez, El estudio de los Edificios de espectáculos.... Op cit.

8. Este gusto por lo clásico se manifestó en la iconografía real (los monarcas eran representados como emperadores romanos), en el coleccionismo (grandes colecciones de escultura clásicas como la de la casa de Alba o la de Francisco de Bruna y Ahumada en Sevilla, entre otros) y en otros ámbitos como en la enseñanza de arquitectura, escultura y pintura ofertadas por la Real Academia de Bellas Artes de San Fernando de Madrid.

9. D. Rodríguez Ruiz, La memoria frágil. José de Hermosilla y las Antigüedades Árabes de España. Madrid, 1992; J. Maier y J. Salas, Comisión de antigüedades de la Real Academia de la Historia. Andalucía. Catálogos e índices, Madrid, 2000; J. Salas, La recuperación del patrimonio arqueológico de Andalucía durante la Ilustración (1736-1808), Sevilla, 2005; J. Maier, Noticias de antigüedades de las actas de sesiones de la Real Academia de la Historia (1834-1874), Madrid, 2008; M. Almagro Gorbea, y J. Maier Allende (eds.) De Pompeya al Nuevo Mundo: La corona española y la arqueología en el siglo XVIII, Madrid, 2012; J. Salas, "El conocimiento y divulgación del arte hispanomusulmán en la Europa romántica: importancia de la obra de James Cavanah Murphy”, en MDCCC 1800 (4). pp. 67-90, 2015.

10. E. Gran-Aymerich, El nacimiento...op. cit.

11. Sobre la antigüedad en la historiografía del XVIII ver G. Mora, Historias... op.cit; D. Rodríguez Ruiz y M. Morán Turina, El legado de la antigüedad. Arte, arquitectura y arqueología en la España moderna, Madrid, 2001; J. Beltrán, "La antigüedad romana como referente para la erudición española del siglo XVIII". Illuminismo e Ilustración. Le antichità e i loro protagonosti in Spagna e in Italia nel XVIII secolo, Roma, 2003; Beltrán y Belén, el clero...op. cit.; M. Romero, Historias antiguas. Libros sobre la Antigüedad en la España del 
Los estudios de antigüedades, ya sean dentro de un corte anticuarista o pre-arqueólogico, proliferaron a lo largo del siglo XVIII como lo demuestran el aumento de los proyectos y las publicaciones en este ámbito. Estas antigüedades eran estudiadas de manera exhaustiva, con mediciones escrupulosas y en las que las representaciones gráficas eran parte imprescindible e incuestionable.

Los viajes realizados durante el siglo XVIII fueron uno de los motores que promovieron el estudio de las antigüedades en la Europa del setecientos. Tuvieron su origen en la Inglaterra del XVII, cuando empezó a considerarse como una parte necesaria en la formación académica de los jóvenes aristócratas ingleses.

A pesar de que los estudios de antigüedades se concentraban en el período clásico, promovidos por las Reales Academia de la Historia ${ }^{12}$ y la de Bellas Artes de San Fernando ${ }^{13}$ en España, existieron trabajos dedicados a los restos precolombinos que llegaron a suscitar un interés real y académico hasta entonces desconocidos. No obstante, este interés existió desde los primeros momentos de la conquista americana, aunque exclusivamente desde una perspectiva coleccionista, tanto desde el ámbito privado como real. La mayoría de estos vestigios pasaron a adornar los distintos palacios reales que fueron destruidos en sucesivos incendios a lo largo del siglo XVIII y, como consecuencia directa, provocó la desaparición de un gran número de restos antiguos de estas culturas transoceánicas.

Una de las instituciones que contribuyó en la promoción de estos trabajos fue el Real Gabinete de Historia Natural ${ }^{14}$, que participó de manera colateral en la redacción de las instrucciones para la recogida de objetos y estudio de los edificios precolombinos. En 1752, bajo el mandato de Fernando VI, Antonio de Ulloa ${ }^{15}$ creó y dirigió la Casa de Geografía y Gabi-

siglo XVIII, Madrid, 2005; J. Salas, La arqueología en Andalucía durante la Ilustración (1736-1808). Anejos de la Revista Mainake, 2, Málaga, 2010; M. Almagro y J. Maier, De Pompeya al nuevo mundo... op.cit.

12. M. Almagro-Gorbea y J. Maier (eds.), 250 años de la Arqueología y Patrimonio. Documentación sobre Arqueología y Patrimonio Histórico de la Real Academia de la Historia, Catálogo del Gabinete de Antigüedades, Madrid, 2003; M. Almagro-Gorbea y J. Maier, "La Real academia de la Historia y la arqueología española en el siglo XVIII", Iluminismo e Ilustración. Le antichità e i loro protagonista in Spagna e in Italia nel siglo XVIII. Real Academia de la Historia- Patriminio Nacional, Madrid, 2012.

13. C. Bedat y E. Lafuente, La Real Academia de Bellas Artes de San Fernando (1744-1808): contribución al estudio de las influencias estilísticas y de la mentalidad artística en la España del siglo XVIII, Madrid, 1989; J. García Sánchez, "La Real Academia de San Fernando y la Arqueología”, Academia, 106-107, 2008, 22-41.

14. El Real Gabinete de Historia Natural se dedicaba al estudio y recogida de los «objetos raros y curiosos» procedentes del mundo animal, mineral y vegetal. Ver J. Alcina Franch, Anticuarios o arqueólogos. Historia antigua de la Arqueología en la América Española, Barcelona, 1995; V. Losada y C. Varela (eds). Actas del II Centenario de Antonio de Ulloa, Sevilla, 1995.

15. Sobre Antonio de Ulloa y su actividad científica ver A. Ulloa, Noticias americanas: entretenimientos físico-históricos sobre la América Meridional y la Septentrional Oriental, Madrid, 1792 (reedición de 2007); A. Guirao de Vierna, "Notas para la clasificación de las expediciones españolas del siglo XVIII a América", en Estudios sobre la historia de la ciencia y de la técnica II, IV Congreso de la Sociedad Española de Historia de las Ciencias y de las Técnicas. Esteban, M., García, N., González, L., Jalón, M., Muñoz, F. y Vicente, I. (coords). Valladolid, 1986, pp. 585-595; P. Cabello, Política investigadora de la época de Carlos III en el área Maya. Descubrimiento de Palenque y primeras excavaciones de carácter 
nete de Historia Natural con el objetivo de albergar todos los restos del «Reino animal, mineral y vegetal» procedentes de las expediciones. Aun teniendo en cuenta que su propuesta prestaba especial atención a la botánica, pues el rey buscaba a través de la misma la salud de sus súbditos ${ }^{16}$, en sus viajes por la América española, entró en contacto con aquellas culturas precolombinas ya desaparecidas que despertaron en él una gran atracción. Ese interés se materializó posteriormente en la recogida, estudio y excavaciones de determinados yacimientos precolombinos que le proporcionaron un amplio conocimiento de dichas antigüedades.

Esa experiencia directa con los restos precolombinos se manifestó en la redacción de un número determinados de artículos incluidos en su instrucción de 1777, que analizaremos más adelante. Dicha instrucción estaba dedicada a la recogida de restos del «Reino animal, mineral y vegetal» de la América española que pasarían a formar parte de las colecciones del Real Gabinete de Historia Natural.

En 1755, debido a la caída en desgracia de su protector, el marqués de Ensenada ${ }^{17}$, Antonio de Ulloa dimitió, dejando bajo otros directores la dirección del Gabinete, en principio, fieles a sus objetivos originarios.

En 1771, Carlos III fundó el Real Gabinete de Historia Natural bajo la dirección de Franco Dávila ${ }^{18}$, quien adquirió toda su colección privada en las que se incluían objetos arqueológicos americanos. El riguroso registro que Franco Dávila tenía de su colección ha permitido obtener un conocimiento exhaustivo de todas sus piezas. Bajo su dirección, se puso en marcha la redacción de lo que constituye el objeto de análisis de este trabajo: las instrucciones para el estudio de las "producciones curiosas de la Naturaleza» en el que se incluyeron algunos artículos relacionados con las antigüedades precolombinas. Esto propició la llegada de numerosos restos arqueológicos al Gabinete, aunque no siempre se sabía con exactitud su procedencia ni cómo habían sido encontrados debido a la ausencia o desaparición de los

científico, Madrid, 1992; P. Cabello, "El Museo de América”, en Anales del Museo de América, 1 (1993), pp. 11-21; J. Alcina Franch, Anticuarios...op.cit; V. Losada y C. Varela (eds). Actas del II Centenario... op.cit.; A. Gutierrez Escuder "Antonio de Ulloa: un científico ilustrado y su crítica opinión sobre el índigena americano", en Arancaria, vol. 2, n³, 2000; P. Cabello "La formación de las colecciones privadas americanas en España: evolución de los criterios”, en Anales del Museo, 2, 2001, 303-318; A. Montesinos, La traducción científica en España en el siglo XVIII. Estudio de la versión española (17851805) de la Histoire Naturelle de Buffon por J. Clavijo y Fajardo, Valencia, 2011.

16. J. Pérez-Rubín Feigl, "Las colecciones marinas institucionales no docentes en Madrid (1776-1893)", Boletín de la Real Sociedad Española de Historia Natural, Sección Aula, Museos y colecciones, I, 2014, 91112, p. 93.

17. J. Maier reflexiona sobre el importante papel de los Secretarios de Estado y otros altos cargos españoles o americanos- en la institucionalización de la Arqueología en nuestro país, y destaca al marqués de la Ensenada, entre otros. J. Maier "La corona y la institucionalización de la arqueología en España” en M. Almagro Gorbea, y J. Maier Allende (eds.) De Pompeya al Nuevo Mundo...op.cit, p. 336.

18. Ma A. Catalayud, Pedro Franco Dávila y el Real Gabinete de Historia Natural, Madrid, 1988. 
informes que los acompañaban, como el caso de los objetos procedentes de una excavación en Cajamarca en $1764^{19}$.

\section{Las Instrucciones emitidas en el siglo XVIII por las instituciones españolas en las que se contempla el estudio de las antigüedades americanas}

La Real Academia de la Historia, la de Bellas Artes de San Fernando, el Gabinete de Historia Natural y la Corona, promovieron distintos proyectos para el estudio de las antigüedades en España y en la América española, como se ha comentado anteriormente. Estos proyectos tenían una misma finalidad, aunque sus enfoques fueran distintos: el enaltecimiento del orgullo nacional y el prestigio de las instituciones que lo promovían. Pero no sólo las instituciones eran las promotoras de estos estudios, sino que también se realizaban por iniciativa privada. Por supuesto, existieron eruditos locales que pretendían ennoblecer su ciudad o, como ocurre en la América española, utilizarlos como distintivo de ese sentimiento nacional que estaba surgiendo a finales del XVIII y que desembocó en la independencia paulatina de los territorios americanos pertenecientes a la Corona española.

Los proyectos promovidos por las citadas instituciones estaban sujetos a unas instrucciones en las que se detallaba la recogida y estudio de las antigüedades. Las prescripciones contenidas en ellas, exigían la validación de datos y la vigilancia del cumplimiento de las mismas por parte de todos los agentes implicados ${ }^{20}$. En este trabajo recogemos las instrucciones emitidas en el siglo XVIII para constatar la evolución desde una concepción anticuarista hasta una nueva mentalidad pre-arqueológica y a la instrucción y el Oficio precursor de la misma, referidos a los trabajos en Palenque.

Tanto la Instrucción de 1776 de Franco Dávila como la de 1777 de Antonio de Ulloa, a pesar de estar centradas en el «Reino Animal, Mineral y Vegetal», dedicaban unos apartados a los restos arqueológicos que iban a parar, junto con los anteriormente citados, al Gabinete de Historia Natural ${ }^{21}$.

19. E. Lanuza y Sotelo, Viaje ilustrado a los reinos del Perú, Lima, 1998; E. Martínez, M. De Pazzis (eds.), Ilustración, ciencia y técnica en el siglo XVIII español, Valencia, 2011.

20. Figueroa dice en relación a esta cuestión: "La exigencia de rubricar las respuestas y refrendarlas por un escribano tendía a asegurar la calidad de la información de la cual dependían a su vez las decisiones políticas tomadas en la metrópolis" (p.127) Figueroa, M. "Cuestionarios, instrucciones y circulación de objetos naturales entre España y América (siglos XVI y XVIII)”, Anuario del Centro de Estudios Históricos "Prof. Carlos S. A. Segreti", año 12, n 12, 2012, 121-136.

21. Ma A. Catalayud, Catálogo crítico de los documentos del Real Gabinete de Historia Natural, Madrid, 2000 .

Revista de historiografía 26, 2017, pp. 317-334 
TABLA 1. Instrucciones relacionadas con el estudio de las antigüedades americanas.

\begin{tabular}{|l|c|c|}
\hline \multicolumn{1}{|c|}{ INSTRUCCIONES } & INSTITUCIÓN & AÑ \\
\hline $\begin{array}{l}\text { Instrucción redactada por Franco Dávila para } \\
\text { la recogida de producciones curiosas de la } \\
\text { Naturaleza }\end{array}$ & $\begin{array}{c}\text { REAL GABINETE DE HISTORIA } \\
\text { NATURAL }\end{array}$ \\
\hline $\begin{array}{l}\text { Instrucción redactada por Antonio de Ulloa } \\
\text { para la recogida de producciones curiosas de } \\
\text { la Naturaleza }\end{array}$ & REAL GABINETE DE HISTORIA & \multirow{2}{*}{1777} \\
\hline $\begin{array}{l}\text { Oficio redactado por José de Estachería y } \\
\text { dirigido a Josef Antonio Calderón para la } \\
\text { inspección de las ruinas de la ciudad de Pa- } \\
\text { lenque. }\end{array}$ & VIRREINATO DE GUATEMALA \\
\hline $\begin{array}{l}\text { Instrucción redactada por José de Estachería } \\
\text { y dirigido a Antonio Bernasconi para el es- } \\
\text { tudio de las ruinas de la ciudad de Palenque }\end{array}$ & VIRREINATO DE GUATEMALA & \multirow{2}{*}{1784} \\
\hline
\end{tabular}

El Consejo de Indias fue la institución encargada de la redacción de la Historia de América hasta 1755, pasando posteriormente este cometido a la Real Academia de la Historia con el cargo de «empleo de Cronista Oficial de Indias». Sin embargo, el Consejo seguía teniendo la potestad de aprobar o rechazar los proyectos planteados por la Academia -por ejemplo, cuando desestimó la redacción de una historia de América por virreinatos en 1762-. El argumento esgrimido fue la falta de visión de conjunto y la centralización del discurso histórico en batallas y crónicas, obviando su evolución política, social y económica. Otra situación similar fue cuando Carlos III ordenó la redacción de una Historia de América para desmentir las acusaciones contra España formuladas en la «Historie philosophique et politique des ètablessiments et de Commerce des europeens dans les deux Indes» de Guillaume Thomas Francois Raynal (Amsterdan, 1770) y «History of America» de William Robertson (Londres, 1777). La Real Academia de la Historia, cronista oficial, creyó ser la indicada para este trabajo, pero Carlos III no quería que tal poder recayese en manos de la Academia porque, entre otras cuestiones, no estaba de acuerdo con la estructura que planteaba. Ante esta situación, el monarca, asesorado por el Consejo de Indias, nombró a Juan Bautista Muñoz «Cosmógrafo Mayor de Indias», encargándole realizar esta labor. La Academia no estuvo de acuerdo con esta designación, pues revindicaba su posición como cronista oficial, por lo que interpuso todo tipo de trabas e impedimentos a la actividad de Muñoz. Para salvar esta situación, Pedro Rodríguez de Campomanes propuso a dicha institución el nombramiento de Muñoz como académico. De esta manera, la 
Academia participaba, en cierta medida, en la redacción de la Historia de América. Juan Bautista Muñoz viajó por toda España visitando los archivos privados y oficiales recogiendo un número elevadísimo de documentos que, en un principio, pasaron a depositarse en el Archivo de Simancas. La residencia oficial de Muñoz estaba en Sevilla y para facilitarle el control y manejo de los documentos se dispuso terminar las obras de la Casa de Lonja de la ciudad hispalense para albergarlos. En 1785, toda la documentación recogida por Juan Bautista Muñoz pasó al Archivo General de Indias, donde se encuentra actualmente. Este ilustre cronista fue uno de los artífices que promovieron el estudio de Palenque de Antonio del Río en 1786.

La Academia de la Historia, a pesar de ser la encargada de la redacción de la Historia de América, no participó en la redacción de las instrucciones que nos ocupan ni en la promoción de estudios desarrollados en la América española. Estos primeros trabajos, realizados en la segunda mitad del siglo XVIII, estuvieron sujetos a las instrucciones emitidas por el Real Gabinete de Historia Natural para el estudio del «Reino Animal, Vegetal y Mineral», dedicándole un apartado al estudio de las antigüedades. Los informes emitidos eran trasladados al Gabinete junto con los objetos recogidos, no obstante, como hemos podido constatar, también se han encontrado copias de esos informes en la Real Academia de la Historia. A pesar de que las instrucciones no eran redactadas en exclusiva para el estudio de las antigüedades precolombinas, los informes relativos a las ruinas de Palenque estuvieron sometidos a unas disposiciones propias redactadas por la autoridad competente. Éstas se centraron en qué debía estudiarse in situ o por el contrario extraerse para enviar posteriormente el informe y los restos arqueológicos al Gabinete de Historia Natural. También debemos tener presente la existencia de otros estudios de monumentos arquitectónicos que fueron realizados por eruditos locales, atraídos por ese pasado glorioso, y con una intención clara de su utilización para fomentar ese incipiente nacionalismo americano. En todos estos estudios era obligatorio incluir la representación gráfica de los restos edilicios, pero nada se especificaba sobre cómo debían dibujarse, dejándolo al criterio del arquitecto y/o ingeniero comisionado.

En las siguientes líneas vamos a analizar las instrucciones mencionadas en la tabla anterior. Debemos aclarar que el Oficio redactado por José de Estachería y dirigido a Josef Antonio Calderón para la inspección de las ruinas de la ciudad de Palenque, está incluido en el apartado dedicado a la Instrucción redactada por José de Estachería y dirigido a Antonio Bernasconi para el estudio de las ruinas de la ciudad de Palenque, ya que se trata de un precedente de la misma. 


\section{Instrucción de 1776 redactada por Pedro Franco Dávila para la recogida de las producciones curiosas de la Naturaleza}

En 1776 se dirigió una circular firmada por el marqués de Grimaldi, el entonces ministro de Estado, a todas las autoridades que gobernasen en los dominios de la corona española, en la que se informaba de lo siguiente:

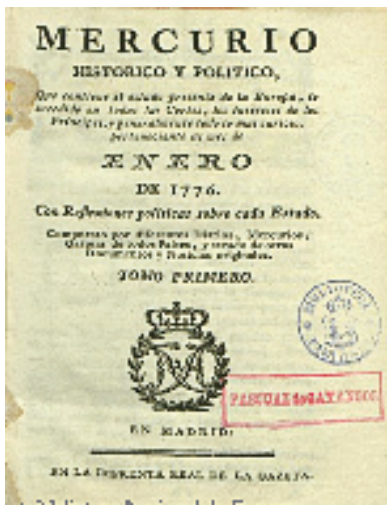

FIG. 1. Portada revista Mercurio Histórico Político en la que se publicó la instrucción para la recogida de las producciones de la Naturaleza redactada por Franco Dávila
El Rei ha establecido en Madrid un Gabinete de Historia Natural en que se reunan no solo los Animales, Vegetales, Minerales, Piedras raras, y quanto produce la Naturaleza en los vastos Dominios de S.M. sinó tambien todo lo que sea posible adquirir de los extraños. Para completar, y enriquecer las séries y colecciones del real Muséo en cada una de sus clases, conviene que los sujetos que mandan en las Provincias y Pueblos de los reinos Españoles, cuiden ahora y en lo sucesivo de recoger y dirigir para el gabinete de Historia Natural las piezas curiosas que se encuentren en los distritos de su mando.

La circular venía acompañada de una instrucción, redactada por Pedro Franco Dávila, en la que se detallaba los animales, vegetales y minerales que debían ser recogidos e incluso su proceso de embalsamamiento, si era necesario. También se establecieron las directrices sobre cómo debían ser los informes, clasificación y el empaquetamiento para el envío. En éste sentido, el objetivo principal de Dávila, como indica Pérez-Rubín, era conseguir el mayor número de ejemplares posible para enriquecer el Real Museo y así contribuir a la instrucción de los españoles con la exhibición pública de los mismos, como finalmente se hizo, pues el Gabinete consiguió abrir sus puertas a finales del año 1776

Sin embargo, la dedicación a los restos antiguos es muy somera y sólo hace mención a los objetos muebles calificándolos de «Curiosidades del Arte»:

Como la intención del Rei es completar quanto sea posible su Gabinete, no solamente de las substancias comprehendidas en los tres Reinos de la naturaleza, sinó tambien de otras curiosidades del Arte, como son Vestidos, Armas, Instrumentos, Muebles, Máquinas, Ídolos, y otras cosas de que usaron los Antiguos Indios ú otras Naciones, será mui estimable qualquier Pieza de aquella clase que pudiere adquirir, como por ejemplo algunas antiguallas de los Indios Quipos, y otros que en el dia subsisten.

Pedro Franco Dávila, con este breve párrafo dedicado a las antigüedades, nos revela que estamos ante un coleccionista sin más aspiraciones que la de recoger el mayor número posible de restos para engrosar la colección del Real Gabinete. Su falta de formación en esta disciplina ocasionó que manifestara un interés decorativo y expositivo más que un afán por estudiar desde el punto de vista histórico estos vestigios arqueológicos. No obstante, pode- 
mos reconocer en estas instrucciones y su interés expositivo una finalidad eminentemente didáctica, pues en ellas declara que su depósito en el museo tiene como intención «el beneficio y la instrucción pública de la nación», aunque según el trabajo de Martín, habría que esperar un par de décadas para que a estas exhibiciones se le sumaran la impartición de lecciones para completar dicho fin.

Sólo un año más tarde, la postura del Real Gabinete ante los restos antiguos de la cultura precolombina cambiará radicalmente con la instrucción redactada por Antonio de Ulloa en 1777.

\section{Instrucción de 1777 redactada por Antonio de Ulloa para el Real Gabinete de Historia Natural}

En esta instrucción, Antonio de Ulloa realiza una explicación más detallada para el estudio de las antigüedades precolombinas que la que expuso su antecesor, Franco Dávila, un año antes. Está compuesta por nueve artículos, estando los primeros ocho dedicados en exclusividad a las antigüedades precolombinas mientras que el noveno se refiere a la obligatoriedad de la recogida de las vestimentas actuales de los indios.

Antonio de Ulloa no era un coleccionista sino un científico sin formación específica en historia, pero como hijo de su tiempo, se caracterizaba por una gran curiosidad que le llevó a ahondar en disciplinas que no eran de su competencia. En sus expediciones entró en contacto con los restos de antigüedades precolombinas que le procuraron un interés por la historia de la América española materializándose en las instrucciones y en la redacción de su obra «Noticias americanas: entretenimientos físicohistóricos sobre la América Meridional, y la Septentrional Oriental: comparación general de los territorios, climas y producciones en las tres especies Vegetal, Animal y Mineral de los indios de aquellos países, sus costumbres y usos, de las petrificaciones de los cuerpos marinos y de las antigüedades» ${ }^{22}$.

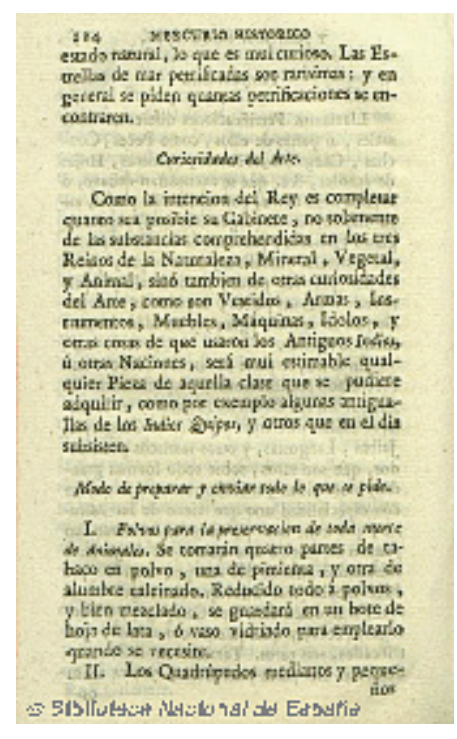

FIG. 2. "Curiosidades de arte" de la instrucción para la recogida de las producciones de la Naturaleza redactada por Franco Dávila.

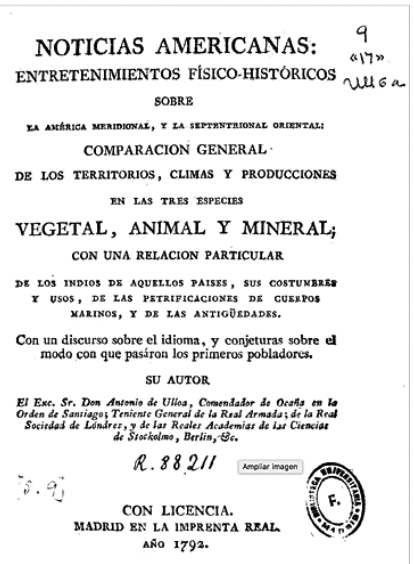

FIG. 3. Noticias Americanas de Antonio de Ulloa.

22. Ulloa, A. de. Noticias americanas: entretenimientos físico-históricos sobre la América Meridional, y la Septentrional Oriental: comparación general de los territorios, climas y producciones en las tres especies 
A diferencia de Pedro Franco Dávila, Antonio de Ulloa formaba parte de esa élite intelectual que puso en marcha una nueva metodología de estudio en la que los restos arqueológicos se convirtieron en una fuente de información no contaminada para la redacción de documentos históricos. Esta postura metodológica, unida a los amplios conocimientos sobre las antigüedades precolombinas, le permitió redactar nueve artículos referidos a la cuestión en la citada instrucción. Su experiencia, así como «su amor al progreso de las ciencias y su bondad» le fueron reconocidas en vida, pues figuras de la época como el noble brigadier Alessandro Malaspina, en las cartas que le dirigió, lo reconocía como gran autoridad dentro de la marina española, le manifestaba su admiración y le pedía consejo acerca de su expedición, que emprendió en $1788^{23}$.

En el primer artículo aclara la importancia trascendental de la recogida y estudio de estos restos para la redacción de la historia de un país. El hecho de que Ulloa considerase necesaria su inclusión, pone de manifiesto que en la España de finales del siglo XVIII seguía existiendo un anticuarismo tan acusado que impedía la aceptación de estas nuevas líneas de estudios en las que los restos arqueológicos pasaban de ser simples objetos de coleccionista a portadores de información histórica: «Uno. Las antigüedades dan luz de lo que fueron los Países en los tiempos más remotos y por ellas se saca el conocimiento del aumento y disminución que han tenido: con este motivo se procura investigar lo conducente a su averiguación, dando noticia de los vestigios que permanezcan en algunos parajes».

En los siguientes artículos hace una distinción entre los restos inmuebles y muebles dividiéndolos en distintas tipologías. Los restos inmuebles, denominados en conjunto como «Edificios antiguos», englobaban un concepto muy amplio porque hacía referencia a todo tipo de edificaciones, desde restos de viviendas hasta tumbas o muros defensivos. No se especificaba cómo debían redactarse esos informes o si era necesario incluir un dibujo arquitectónico de los mismos, pero se dejaba claro que debía recogerse la mayor información posible en los informes porque eran cruciales para conocer la historia de esos pueblos.

En relación a los restos muebles hace una distinción más precisa, dedicando desde el artículo dos hasta el siete a objetos tales como recipientes de cualquier material, armas, aperos de labranza, ídolos y adornos ${ }^{24}$ :

Dos. Estas noticias serán de las ruinas de Edificios antiguos de Gentilidad de cualquier materia que sea; de las paredes, cercas, muros, zanjas o fosos; de los entierros o sepulturas; de los Adoratorios o templos; de las casas o chozas que habitaban con expresión de sus figuras, capacidades, entradas y distribuciones internas. Tres. De las vasijas usuales para todo género de servicio de barro o de otras materias. Cuatro. De las Herramientas para cultivar la tierra hechas de piedra, de cobre, de huesos de animales, o de maneras recias. Cinco. De las Armas, como Arcos, Flechas, Lanzas, Dardos, Ondas, etc., con sus nombres según se conserve la noticia en la lengua.

Vegetal, Animal y mineral de los indios de aquellos países, sus costumbres y usos, de las petrificaciones de los cuerpos marinos y de las antigüedades. Madrid, 1792.

23. Puig-Samper, M.A. Alejandro Malaspina. Estudio Crítico. Madrid, Fundación Ignacio Larramendi, 2016.

24. P. Cabello, Política investigadora...op. cit. p.17 
Seis. De los Digecillos, o Ídolos igualmente de distintas materias y de toda suerte de piezas usuales. Siete. De los adornos, divisas o insignias que usaban los antiguos Indios, y esto como lo antecedente, se encuentra en sus sepulcros o entierros.

El artículo octavo hace una especial mención a la importancia de registrar los sepulcros, porque según se indica, a través de ellos se podían localizar gran número de restos para obtener información de estas culturas desaparecidas: «Ocho. Generalmente de todas las cosas que indican ser de aquella antigüedad, pues no es extraño verse en los mismos sepulcros de otras especies, y aun de algunos retazos detexidos de Pita que indican ser de los ropajes que usaban».

Estos artículos muestran los amplios conocimientos sobre la cultura precolombina de Ulloa adquiridos durante sus expediciones, anteriores a la redacción de esta instrucción ${ }^{25}$, así como su gran interés por la recuperación de la información que se pudiera obtener de los vestigios.

\section{Oficio redactado por José de Estachería y dirigido a Josef Antonio Calderón para la inspección de las ruinas de la ciudad de Palenque e Instrucción para el reconocimiento de las ruinas de Palenque de 1785}

Esta instrucción se redacta a partir del informe entregado por José Antonio Calderón, Teniente Alcalde Mayor de Palenque, sobre los restos de una población ubicada en sus dominios. Ese informe se redactó a partir de un oficio previo de José Estachería ${ }^{26}$, Presidente de la Audiencia, Capitán General y Gobernador de Guatemala, el 28 de noviembre de 1784, en el que se ordenaba a José Antonio Calderón su desplazamiento hasta las citadas ruinas para la realización de un informe individualizado de todo lo hallado ${ }^{27}$. Este oficio cumple dos objetivos: el primero acatar lo indicado en la instrucción de 1776 en la que Carlos III ordena a las autoridades de todos los dominios de la corona española la recogida de antigüedades para pasar a engrosar la colección del Real Gabinete de Historia Natural, y el segundo, utilizar esos restos arqueológicos para la redacción de una Historia de América que conformara el principio de la nueva metodología ilustrada para el estudio de la historia. Esta intención ya se pone de manifiesto en el primer artículo de la parte dedicada a las antigüedades de la instrucción de Ulloa de $1777^{28}$, como vimos anteriormente. Sin embargo, Estachería va más allá en sus propósitos porque también expone que deben utilizarse para enaltecer el honor de la Nación, pero no de la guatemalteca, sino de la española, habida cuenta que se estaba viendo muy perjudicada con las publicaciones inglesas y francesas citadas en este mismo trabajo. Tampoco debemos olvidar el otro factor que ya hemos mencionado: la gestación de un sentimiento nacionalista americano que culminaría unos años más tarde con la independencia

25. P. Cabello, Política investigadora...op. cit.

26. M. Almagro, y J. Maier, "La corona..." loc.cit.

27. Texto citado y transcrito en P. Cabello, Política investigadora...op. cit. pp. 78-79.

28. Citado en P. Cabello, Política investigadora...op. cit. pp. 17-18. 
de estos territorios. Por tanto, el estudio de estos restos más que ayudar a la consolidación del poder español en las colonias americanas lo perjudicó, desde el momento en que fue utilizado como un arma nacionalista e identitaria de los insurrectos que promovieron y alentaron la independencia.

Estachería era consciente del escaso nivel de conocimiento sobre las antigüedades de la América española existente entre los estudiosos españoles y ésto, unido a su formación en cultura clásica, hacía imposible la redacción de una instrucción adecuada para estos restos. Para salvar el obstáculo, Estachería redactó este oficio poniendo especial interés en el modo en que debía realizarse la recogida, indicando a Calderón que la obtención de información de todo lo que observase se hiciera tanto en conjunto como de manera individualizada, para de este modo poder obtener un mayor conocimiento de los restos. Calderón entregó el informe de su inspección el 15 de diciembre de 1784 y el 27 de enero de 1785, Estachería envió una instrucción a Antonio Bernasconi ${ }^{29}$, Arquitecto de las Obras Reales de Guatemala, para que estudiase los restos de la ciudad de Palenque ${ }^{30}$.

A consecuencia de este oficio se redactan las «Instrucciones para el reconocimiento de las ruinas de Palenque. De José Estachería a Antonio Bernasconi. Real Palacio (Guatemala), 29 de enero de 1785 (en copia de 30 de enero de 1785) $»^{31}$, que se componen de diecisiete capítulos. En el primero se expusieron los objetivos a alcanzar durante la investigación, denominados en la instrucción «obgetos». Con estos cinco «obgetos» pretendía dar las pautas para conocer, de manera pormenorizada la antigüedad, el origen, las actividades comerciales, la importancia de la ciudad, su orden arquitectónico y, por supuesto, la causa de su abandono.

Desde el capítulo dos hasta el quince especifica qué debe estudiarse o recogerse para conseguir cada uno de los «obgetos» expuestos en el primer capítulo. Para alcanzar su primer «obgeto», dedicado a la averiguación de su antigüedad y origen, Estacharía reclama el dibujo exhaustivo de todas las estatuas o una de cada tipo. También ordena la extracción de aquellos restos mejor conservados como prueba de la grandiosidad del descubrimiento e indica cómo deben ser transportados hasta Guatemala. Desde allí, estas antigüedades fueron enviadas a

29. M. Almagro, y J. Maier, “La corona...” loc.cit.

30. Cabello recoge pormenorizadamente los trabajos arqueológicos llevados a cabo en el siglo XVIII en Palenque, aclarando que en la centuria que nos ocupa, el más conocido es el último de los tres conocidos, realizado por Antonio del Río y el dibujante Almendáriz. Cabello entiende que "el conjunto de las tres prospecciones (1784,1785 y 1787) conforman las primeras expediciones plenamente científicas en América, que siguieron una sistemática plenamente documentada con informes y dibujos..." Cabello, P. "La arqueología ilustrada en el Nuevo Mundo" en De Pompeya al Nuevo Mundo: La corona española y la arqueología en el siglo XVIII, Almagro, M. y Maier, J. (coords.) 2012, p. 270. Por su parte, Bernasconi a partir de 1785, levantó mapas de sitio (veintidós edificaciones) y algunos dibujos de detalle de ciertas edificaciones, y procedió a la recogida de diversas piezas edilicias: un fragmento de estuco (una cabeza antropomorfa), un panel de piedra y un mascarón de arcilla. González Cruz, A. "Dos siglos de descubrimientos arqueológicos en Palenque, Chiapas”, en A. Ma , Parrilla, A. Sheseña y R. López (coords.) Palenque. Investigaciones recientes. Universidad de Ciencias y Artes de Chiapas. México, 2015, pp. 15-59, p. 17.

31. Citado y transcrito en Cabello, Citado en P. Cabello, Politica investigadora...op. cit. pp. 90-99. 
España, junto con el informe de Antonio Bernasconi para que formaran parte de la colección del Gabinete de Historia Natural ${ }^{32}$.

Capitulo 1. ${ }^{\circ}$

Son obgetos de revisión.

Primero: hacer merito de todo quanto pueda influir para formar idea de la antiguedad de aquella fundación; y de lo q e dé luz para inquirir la Nación, ò gentes a quienes debió su origen.

Ynfluirá a los conocim. ${ }^{\text {tos }}$ del primer. obgeto la prolija Ynspeccion que debe hacerse en todas las estatuas de sus trages, calzados, y adornos de caveza, retratando con la $\mathrm{m} .{ }^{\text {or }}$ propiedad que sea posible, á lo menos una de cada clase que parezca diferente. Examinar à fondo las lápidas,

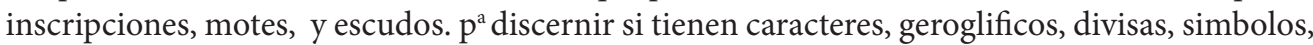
ò cual. ${ }^{\text {a }}$ cosas de las muchas q.e pertenecen al blason, y copiar todas las piezas q ${ }^{\text {e }}$ de este orden puedan ilustrar mas en lo q. ${ }^{\text {e }}$ se quiere averiguar; sacando también de loos sitios en q. ${ }^{e}$ se hallen alg. ${ }^{a}$ ò algunas de aquellas q. ${ }^{\text {e }}$ parezcan mas demostrativas del obgeto, a fin de devastarlas con cuidado, hasta hacerlas facilm. ${ }^{\text {te }}$ portátiles, tratar de su remisión a esta Capital defendiendolas antes con cueros, y las demás cosas que aseguren el que no se rompan las piedras. ò laceren sus divisas.

El segundo «obgeto» se centra en el estudio de las posibles actividades industriales y comerciales desarrolladas en la ciudad. Favoreciendo lo que entendemos como una pretensión de realizar una verdadera aproximación científica al uso de estos elementos edilicios, a este apartado le dedica los capítulos tres, cuatro y cinco en los que ordena un reconocimiento detallado de aquellos edificios con evidencias de actividad comercial e industrial y el examen del entorno para localizar las vías de comercio (marítimas o terrestres). En la instrucción se deja claramente expresada la transcendencia de este «obgeto», pues le resultaba poco creíble que con la recolección de frutos y la ganadería - actividades desarrolladas en ese momento por los indígenas de la zona- hubiesen llegado a la creación de una ciudad tan grandiosa:

Segundo: Qual fué la industria, Comercio, ò medios con $\mathrm{q}^{\mathrm{e}}$. subsistieron sus havitantes. Capit. $^{\circ} 3 .^{\circ}$

El inferior lo concerniente al segundo obgeto, o punto, pide una circunstanciada Ynspeccion de todos aquellos edificios que de cualquiera manera denoten otra cosa que pura avitación, è indiquen haver contenido en si fabricas de alguna manufactura, beneficios de metales, o acuñación de moneda, pues la magnificencia que se atribuye á dha Ciudad por los q. hasta aquí se han acercado a ella, no se puede proceder de nos medios limitados a cosechas de frutos, y crias de ganado como reducidos à solo manutencion, ni el grande fomento q. ${ }^{\mathrm{e}}$ es preciso considerar para las prosperidades q. ${ }^{\text {e }}$ se suponen en aquella poblacion, pudo apoyarse sino en alguno de los principios, y nervios mas solido de riqueza, como son las minas, ò otra precisa especie q. ${ }^{\mathrm{e}}$ facilitase à los pobladores un lucroso comercio activo con q. ${ }^{\mathrm{e}}$ atraer a si la felicidad, y abundancias

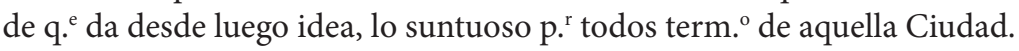

32. J. Alcina Franch, Anticuarios...op.cit.

Revista de historiografía 26, 2017, pp. 317-334 
Estacharía, con el tercer «obgeto», pretende recoger la máxima información a través de un examen exhaustivo de la composición de unos «cerros» ${ }^{33}$ que se encuentran en el interior del recinto de la ciudad. Es curioso constatar como realiza un símil con la erupción volcánica que sepultó a las ciudades de Pompeya y Herculano cuando pide que se busquen restos de «materias q. ${ }^{e}$ dan de si las erupciones de Volcanes» como posible causa del abandono de la ciudad. También solicita un reconocimiento de las ventanas y puertas tapiadas, que Calderón identificó en su informe, para ver si esto estaba relacionado con invasiones o revueltas ciudadanas: «Tercero: Que fatalidad, mocion, ò tragedia causaría la destruccion de aquella Ciudad, y el exterminio de sus habitantes».

El cuarto «obgeto» pretendía conseguir la «magnificencia» que llegó a alcanzar la ciudad. Para ello debían tomarse las medidas de los edificios, registrar todas las estancias u objetos que denotasen el estatus económico de sus dueños, el diámetro total de la ciudad y por supuesto, intentar averiguar si seguían algunas directrices en sus construcciones ${ }^{34}$. Si era necesario, podían realizarse excavaciones para obtener más información de los edificios estudiados. Todas estas construcciones debían estar representadas en un plano de la ciudad donde se identificasen claramente cada una de ellas. Como colofón, pidió que se estudiase detenidamente los restos de una piedra tallada, en principio, según Calderón, perteneciente a un molino, pero que por sus dimensiones Estacharía pensaba que podía tratarse de parte de una máquina con una factura y una funcionalidad más compleja:

Quarto: Saber la entidad, y magnificencia de ella [... Capit. $^{\circ} 13 .^{\circ}$ Entre los examenes prevenidos à los Capitulos $3 .^{\circ}$ y $4 .^{\circ}$ y debe hacerse uno mui individual de la bóveda con que en dis. ${ }^{a}$ de dos quadras se cubre el rio inmediato al Palacio pral. En cuya proximidad parece se hallan dos piedras redondas, una agugereada, y otra sin esta circunst. ${ }^{a}$ como proporcionadas à Molino; pero como no serán estos los unicos vestigios q. ${ }^{\text {e }}$ se conserven alli, y deviendo graduarse por la excesiva extensión de la citada bóveda, respecto à maquina tan sencilla, y limitada como es un molino, que acaso seria otra mas interesante la establecida, reconocerá prolijamente todo el interior $\mathrm{p} .{ }^{\mathrm{a}}$ combinación de los fundamentos q. ${ }^{\mathrm{e}}$ encuentre, formar idea de la q. ${ }^{\mathrm{e}}$ pudo ocupar su considerable extensión.

El quinto «obgeto» encerraba el final de la investigación, porque después de los resultados obtenidos en el desarrollo de los «obgetos» anteriores, Antonio Bernasconi debía emitir una hipótesis sobre los fundadores de la ciudad y antigüedad de la misma:

Capit. ${ }^{\circ} 15 .^{\circ}$ Después de estos conocim. ${ }^{\text {tos }}$ puede con verosimilitud el Arquitecto comisión. ${ }^{\circ}$ conciliar sus juicios conforme al 5. ${ }^{\circ}$ punto, sobre q. ${ }^{e}$ Nacion, y en q. ${ }^{e}$ epoca pudo haver sido, la q. fundó la Ciudad y à este fin llevará los Autores de Arquitectura que expliquen las reglas q. e $^{\circ}$ sucesivam. ${ }^{\text {te }}$ se han ido estableciendo en su orn por las distintas naciones, y segun el curso de los siglos.

33. Parece ser que se refiere a escombros amontonados dentro del recinto de la ciudad.

34. Este objeto vuelve a mostrar esa formación clásica del ilustrado que para el estudio de la arquitectura de otras culturas pide que se establezcan las órdenes, si las hubo, como las que los griegos y romanos seguían en sus edificaciones. 
En el capítulo dieciséis, Estachería exige claridad expositiva de los resultados y cómo deben clasificarse los objetos extraídos para su rápida identificación:

Capit. ${ }^{\circ} 16 .^{\circ}$ Para que las noticias que me produzcan à vista de todo lo que le va advertido en esta Ynst. ${ }^{\text {on }}$ contenga la claridad necesaria, y pueden ordenadam. ${ }^{\text {te }}$ combinarse con las copias q. ${ }^{\mathrm{e}}$ saque de estatuas, escudos $\mathrm{H}^{\mathrm{a}}{ }^{\mathrm{c}}$ como se previene al cap. ${ }^{\circ}{ }^{\circ}{ }^{\circ}$ deverán venir estas señaladas con los números desde el $1 .{ }^{\circ}$ hasta el q. ${ }^{e}$ corresponda a la ultima, y reclamarse por ellos en el informe según le ofrezca citarlas, expresando quantas hay de cada clase.

En esta instrucción, igual que sucede con el oficio dirigido a José Antonio Calderón, sólo mencionan lo que debe ser estudiado, la obligatoriedad de la representación gráfica (artística y arquitectónica) y la recogida de determinados restos. Sin embargo, no mencionan qué tipo de representación arquitectónica se requiere en relación a los edificios (planta, alzado o sección) o qué sistema de mediciones deben emplear. No obstante, en anteriores instrucciones para el territorio hispano, como la de 1752 del marqués de Valdeflores, el pie de hierro y posteriormente el romano eran los utilizados para el estudio de los restos romanos: «6 $6^{\circ}$.- Hará estas dimensiones por el pie de hierro que le habrá de entregar el Director de la Academia, en cuyo poder quedará otro igual al que llevare»- Pero al no tratarse de ruinas romanas el sistema de medición no se indica, si no que se opta por acatar la decisión del arquitecto que realice el estudio.

\section{Conclusiones}

A modo de breve reflexión final y recapitulación, comentaremos algunos aspectos que consideramos relevantes. Los estudios de las antigüedades precolombinas realizados por los españoles en el siglo XVIII, como hemos podido ver en las instrucciones de Dávila y Ulloa, emanaron del Real Gabinete de Historia Natural y se encontraron insertos en proyectos cuyo objetivo principal era la recogida de especies naturales y, por tanto, se vieron determinados por las instrucciones que realmente estaban redactadas para dicho fin, contemplando la recogida de vestigios arqueológicos de manera marginal o complementaria. El interés que movía esta recogida era obtener el máximo número de ejemplares para instruir a los españoles -intención didáctica que también consideramos una novedad interesante frente al simple coleccionismo- o para la investigación con fines terapéuticos. De hecho, Dávila nomina estos objetos como «curiosidades de arte» poniendo de manifiesto su concepción anticuarista. Esto provocó que la parte de las instrucciones dedicada a estos objetos fueran en alguna ocasión sólo pequeñas referencias, o que otras veces no se contemplase un estudio completo de las mismas, en contraste con lo que ocurría con las dedicadas al estudio de las antigüedades en España. No obstante, a pesar de encontrarnos este panorama inicial, y de que el resto de instrucciones del siglo se preocuparon fundamentalmente por la botánica, tan sólo un año después, Ulloa, que representa la nueva perspectiva ante los restos arqueológicos, dedica ocho capítulos de su instrucción a las antigüedades y uno a las vestimentas de los indios, 
realizando toda una declaración de intenciones al señalar la importancia de las mismas para poder redactar la historia de un país.

Debemos resaltar la instrucción destinada al estudio de los restos de Palenque que intenta trazar unas líneas de actuación exclusivamente dedicadas al estudio de dichas antigüedades, pero debemos señalar que dicha instrucción se emitió en la propia colonia y aunque estuvo inspirada por el intento de enaltecer el honor de la metrópoli, también muestra el germen de sentimientos nacionalistas propios. En cualquier caso, podemos concluir que el esfuerzo no estuvo a la altura de lo que encontramos en España o Europa en relación al estudio de las antigüedades clásicas.

Como venimos manteniendo a lo largo de este trabajo, el análisis de la evolución de las instrucciones de Dávila, Ulloa y Estacharía evidencian la evolución desde la perspectiva coleccionista que imperaba hasta el momento hacia un nuevo concepto del vestigio arqueológico como fuente primaria de información, integrante de un valioso patrimonio que enaltece a la nación y que ya no se utiliza para justificar posiciones políticas, sino para reconstruir el pasado. 